\title{
Effect of Carbon Content on the Mechanical Properties of Medium Carbon Steels
}

\author{
Adnan Calik ${ }^{\mathrm{a}}$, Akin Duzgun ${ }^{\mathrm{b}}$, Osman Sahin ${ }^{\mathrm{c}}$, and Nazim Ucar ${ }^{\mathrm{d}}$ \\ a Department of Mechanical Education, Technical Education Faculty, Suleyman Demirel University, \\ Isparta, Turkey \\ b Engineering Faculty, Civil Engineering Department, Ataturk University, Erzurum, Turkey \\ ${ }^{c}$ Physics Department, Art and Science Faculty, M. Kemal University, Hatay, Turkey \\ d Physics Department, Art and Science Faculty Suleyman Demirel University, Isparta, Turkey \\ Reprint requests to N. U.; E-mail: nazmucar@yahoo.com
}

Z. Naturforsch. 65a, 468 - 472 (2010); received December 1, 2008 / revised July 17, 2009

The mechanical properties of medium-carbon steels with a carbon content ranging from 0.30 to $0.55 \mathrm{wt} . \%$ were investigated by tensile and microhardness tests at room temperature. It was observed that the higher carbon content results in an increase in yield stress and ultimate tensile stress, while the elongation remains essentially constant. The results were explained by the hindering of dislocation motion associated with solid solution hardening.

Key words: Medium Carbon Steel; Yield Stress; Ultimate Tensile Stress; Elongation; Solid Solution Hardening.

\section{Introduction}

In the rapid developing industry, steels continue to gain wide use as prospective functional and structural materials because of their good soft-magnetic properties, high strength, good corrosion, and wear resistance coupled with relatively low material cost [14]. Among steels, medium-carbon steels have a carbon content of 0.29 to $0.60 \mathrm{wt} . \%$. They balance ductility and strength and has good wear resistance; used for large parts, forging, and automotive components [5]. It is therefore not surprising that much current research has been directed toward improving plasticity of these steels. Although a number of studies have examined the effect of deformation parameters such as temperature, strain, and strain rate on the plastic behaviour of these steels [6-8], there has been limited research on the mechanical properties of carbon content. It is well known that medium-carbon steels behave in an intermediate manner between high- and low-carbon steel [9]. It has been shown that the stress level and the stress-strain curves depend not only the deformation conditions, but also on the carbon content. In general, as the carbon content increases the hardness of the steel also increases, while the elongation decreases. On the other hand, a survey conducted by Storojeva et al. [10] in these steels has shown that the pearlite lamellar morphology leads to undesirable cold working mechanical properties in highly stressed components, while globular cementite morphology conduces to higher toughness, good cold workability and machinability. In addition, it has been shown that carbon produces a small change in the softening behaviour at deformation temperatures above the nonrecrystallization temperature. However, the kinetics of post-deformation softening have been observed to be significantly retarded with carbon at the deformation temperatures lower than the non-recrystallization temperature due to NB $(\mathrm{C}, \mathrm{N})$ precipitates in NB-steels [11]. With increasing carbon content of the steel the stress ratio parameter $\left(\sigma_{\text {true }} / \sigma_{\text {effective }}\right)$ is found to be higher compared to pure iron with no carbon content in powder metallurgy steels, where $\sigma_{\text {true }}$ is the axial stress, $\sigma_{\text {effective }}$ the effective stress [12]. On the other hand, Mead and Birchenall [13] showed that the carbon content increases the self-diffusion coefficient of iron. The activation energy for the self-diffusion of iron decreases with increasing carbon content. Therefore, it is expected that the higher-carbon steels would have higher recovery rate $[11,14]$.

The effects of carbon content on the hardness of high vanadium high-speed steels have shown that hardness increases sharply as a function of the carbon content with up to $2.25 \%$ and slowly more than $2.25 \%$. 
(a)

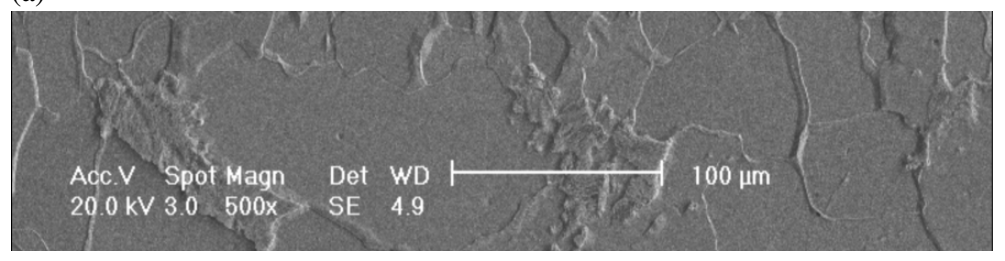

(1)

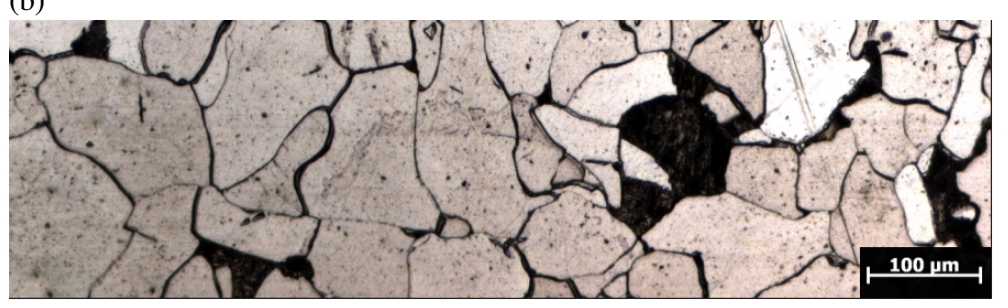

Fig. 1. (a) SEM and (b) optical micrographs of medium-carbon steels.
With the increase in carbon content, the microstructure is changed into the martensite and the retained austenite, as well as the solid solution strengthening of the carbon element [15]. The goal of this paper is to explore the relationship between the mechanical properties and carbon content of medium-carbon steels at room temperature.

\section{Experimental Method}

The steels used for this study were medium-carbon steels. The steels were annealed at $1100 \mathrm{~K}$ for $4 \mathrm{~h}$ to remove potential residual stresses before machining the specimens. Figure 1 shows the microstructure of the annealed medium-carbon steels obtained by Jeol JSM-6400 scanning electron microscope (SEM) and optical microscope. The microstructure shows uniform ferrite and pearlite phase structure. The alloying additions of steels were kept constant apart from the carbon, which varied from 0.30 to 0.55 wt.\% (Table 1). The test pieces used in tensile and microhardness tests were $2 \mathrm{~mm}$ in diameter and $30 \mathrm{~mm}$ in length. The steels were pulled with an Instron type machine at a strain rate of $10^{-6} \mathrm{~s}^{-1}$ room temperature. Load and elongation curves were recorded during the tensile tests and were converted into stress-strain curves. The yield stress $\left(\sigma_{\mathrm{y}}\right)$ and ultimate tensile stress $\left(\sigma_{\mathrm{UTS}}\right.$ were taken to be stress at $0.2 \%$ offset strain and the maximum stress on the stress-strain curve, respectively. To determine the hardness of steels a Vickers microhardness tester with a load of $100 \mathrm{~g}$ was used. Many indentations were made on the surfaces of steels to check the reproducibility of hardness data.
Table 1. Chemical compositions of medium-carbon steels (wt. \%).

\begin{tabular}{lccccccc}
\hline & C & Si & Mn & Cr & P & S & Fe \\
\hline Steel A & 0.30 & 0.18 & 0.76 & 0.16 & 0.04 & 0.01 & Bal. \\
Steel B & 0.41 & 0.19 & 0.80 & 0.18 & 0.04 & 0.05 & Bal. \\
Steel C & 0.49 & 0.18 & 0.78 & 0.21 & 0.01 & 0.01 & Bal. \\
Steel D & 0.55 & 0.18 & 0.77 & 0.19 & 0.02 & 0.04 & Bal. \\
\hline
\end{tabular}

\section{Results and Discussion}

Although pure iron is a weak material, steels have yield stress ranging from 200 to $2000 \mathrm{MPa}$ [16]. The most distinctive aspect of strengthening of iron is the role of the interstitial solutes carbon and nitrogen. These elements also play a vital part in interacting with dislocations and in combining preferentially with some of the metallic alloying elements used in steels

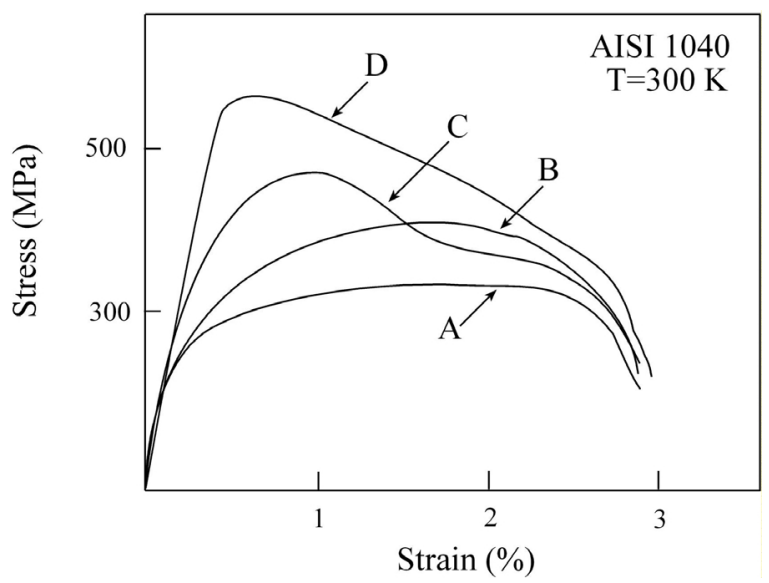

Fig. 2. Stress-strain curves of steels at different carbon content. 


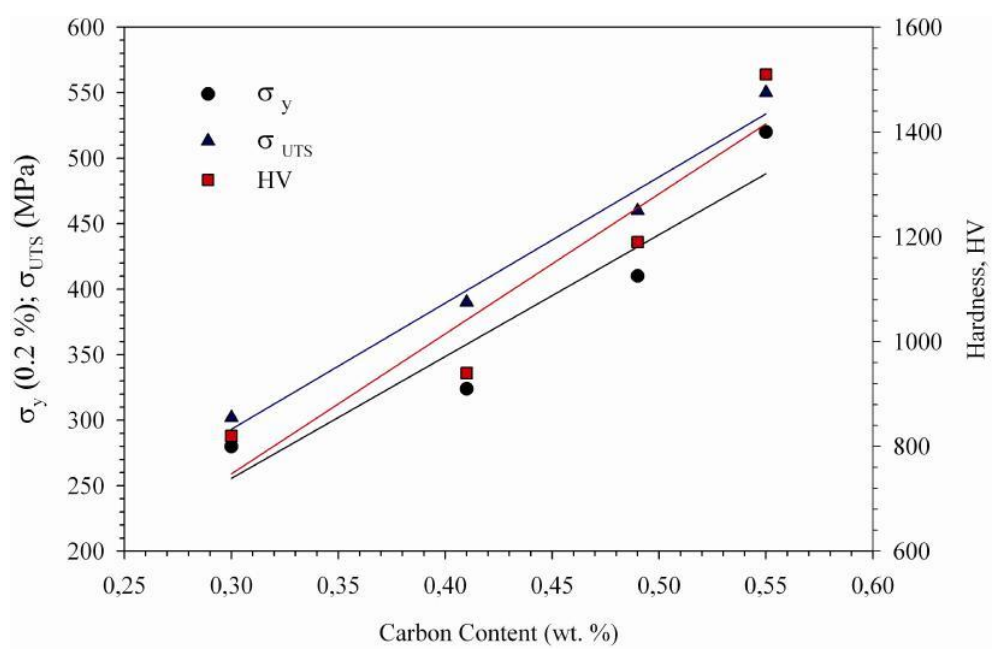

Fig. 3. Variety of yield stress $\left(\sigma_{\mathrm{y}}\right)$, ultimate tensile stress $\left(\sigma_{\mathrm{UTS}}\right)$, and hardness with carbon content changing.
[16]. Typical engineering stress-strain curves obtained from load-elongation curves of steels were given in Figure 2. These curves obtained from steels at room temperature were approximately smooth with no yield drop and they exhibit work hardening to a peak stress followed by softening. It is interesting that the stressstrain curve of the steel A having $0.30 \mathrm{wt} . \%$ carbon content has a long plateau. In literature [17] it has been pointed out that the stress during straining tends towards a saturation stress as a result of a dynamic equilibrium between athermal work hardening (dislocation storage) and thermally activated work softening (annihilation of dislocations). So, the observed plateau may be related to the balance between the work hardening and the work softening. The $\sigma_{\mathrm{y}}$ and the $\sigma_{\mathrm{UTS}}$ of the medium-carbon steels were plotted as a function of the carbon content in Figure 3. Both the $\sigma_{\mathrm{y}}$ and the $\sigma_{\text {UTS }}$ follow a linear relationship with carbon content and increase significantly with the increasing carbon content. Clearly, the carbon content appears to have a specific effect on the tensile behaviour (Fig. 2 and Fig. 3). These results are in good agreement with the other studies in [12,13,18-22]. Collinson et al. [23] reported an effect of the carbon on the stress-strain behaviour in the plain carbon steels for Zener-Hollomon (Z) conditions. They have also shown that the carbon effect only appears in steels with $>0.4$ carbon and under high $\mathrm{Z}$ conditions. Meanwhile, it is well known that the elongation-to-failure is a quantitative measure of ductility, and is taken as the engineering strain which the sample broke [17]. As can be seen from Figure 2, there is no considerable effect of carbon content on the tensile elongation of steels at room temperature. This indicates that the effect of the chemical composition on total elongation is insignificant. In [24], it has been seen that the increase of carbon content results in an increase in strength but a decrease in elongation at room temperature. This result has been explained with the result of microstructural changes with the carbon content. In the present study, the microstructure was not changed with increasing carbon content. We believe that the constant elongation with the increasing carbon content may be the result of unchange in the width of boundaries associated with the mean free path of dislocations. Torre et al. [25] showed that the increase in the ductility (and decrease in strength) are associated with the operation of recovery mechanisms which decrease the boundary volume and total dislocation density causing an increase in the mean free path of dislocations. In addition, the mean free path of dislocations is also an important parameter because the yield strength and hardness increase as the dislocation path length decrease, as in the well-known Hall-Petch effect [26].

The microhardness is not only a mechanical characteristic routinely measured, but, in recent years, it has been developed as an investigation method because it has been established that it is sensitive to structural parameters as well as to mechanical behaviour (yield stress, modulus of elasticity, some secondary relaxation transitions, etc.) [27]. In Figure 3, the hardness changes linearly with the carbon content and there is a considerable increase in hardness with increasing carbon content. We have found the $\sigma_{\mathrm{y}}$ and $\sigma_{\mathrm{UTS}}$ in tension to be about 3.2 and 3.4 of the hardness in steels at room temperature, respectively. These values are given to be 
about 3 in $[17,28,29]$ and changes with the metal or alloy and hardness type (Vickers or Brinell hardness). Our values agree well with those found for martensitic, non-martensitic, and complex phase steels [30]. Sim et al. [31] showed that the carbon content affects mechanical strength of steels by controlling pearlite volume fraction. As indicated above, in the present study, with the increase in the carbon content, the microstructure was not changed. We suggest that the carbon content dependence of the $\sigma_{\mathrm{y}}$, the $\sigma_{\mathrm{UTS}}$, and the microhardness of steels can be explained with the solid solution hardening. The solid solution hardening is an imperative phenomenon governing the plastic behaviour of materials. This phenomenon occurs during the plastic deformation due to the generation and the interaction of dislocations. Corresponding to this, it has been shown that the dislocation multiplication by enhanced precipitation due to higher $\mathrm{C}$ and $\mathrm{Mn}$ is also further increased [32]. Basically, the larger number of dislocations produced, the larger their interaction and, hence, the larger stress is required for the yielding. The solid solution hardening has been explained with a model proposed by Sato and Meshii [33], in which the interaction between solute atoms and a kink on a screw dislocation is explicitly considered, described as misfit strain centres. On the other hand, the strong misfit centres provide greater resistance to the overcoming of solute atoms by dislocations. Therefore, these combined effects on overall dislocation motion generate two antagonistic softhening and hardening effects of the solute atoms [34]. Another model for hardening and softening of alloys has been introduced by Lukac and Balik [35]. They assume that the hardening occurs due to multiplication of dislocations at both impenetrable obstacles and forest dislocations. Annihilation of disloca-

[1] K. Tokaji, K. Kohyama, and M. Akita, Int. J. of Fatigue 2, 543 (2004).

[2] C. Martini, G. Palombarini, G. Poli, and D. Prandstraller, Wear 256, 608 (2004).

[3] P. A. Dearnley and G. Aldrich-Schmith, Wear 256, 491 (2004).

[4] L. Shi and D. O. Northwood, Acta Mater. 43, 453 (1995).

[5] W.F. Smith and J. Hashemi, Foundations of Mater. Sci. and Eng., 4th ed., McGraw-Hill, Higher Education, Boston 2006, p. 388.

[6] M. Sahin, H. E. Akata, and T. Gulmez, Mater. Characterization 58, 10 (2007). tions due to cross slip and climb is considered the dominant softening process. Meanwhile, the deformation behaviour of alloys depends on solute type and content. The hardening is a result of dislocation interaction with atoms in solid solution and other dislocations [36]. Our previous calculations (not presented here) show that the dislocation density $N$ increases significantly with the increasing tensile strain. Clearly, an increase in the carbon content and dislocation density with an increasing strain effectively increases both $\sigma_{\mathrm{y}}$ and $\sigma_{\mathrm{UTS}}$. This is mainly due to dislocation-dislocation interaction and the presence of carbon-rich particles acting as obstacles to dislocation slip. This agrees with Suzuki's theory of solid solution hardening of bcc alloys which has been found to describe the solid solution hardening of various binary Fe-base alloys $[37,38]$. A physical model for the evolution of the flow stress based on a coupled set of evolution equations for dislocation density and (mono) vacancy concentration has also been proposed by Lindgren et al. [39]. In this model, the yield limit is assumed to consist of short and longrange interactions with the dislocation substructure. The effect of carbon on hardening is mainly via the short-range term.

In summary, the measurements of microhardness and tensile tests of medium-carbon steels with the different carbon content ( 0.30 to 0.55 wt.\%) have shown that $\sigma_{\mathrm{y}}, \sigma_{\mathrm{UTS}}$, and hardness increase with an increase of carbon content at room temperature. This fact is related to the effects of solid solution hardening according to hindering dislocation mechanisms of plastic deformation. On the other hand, the constant elongation may be due to unchange in the width of boundaries associated with the mean free path of dislocations.

[7] P. Fernandes and K. Narayan Prabhu, J. Mater. Proc. Technol. 183, 1 (2007).

[8] I. V. Gorynin, V. V. Rybin, I. P. Kursevich, A. N. Lapin, E. V. Nesterova, and E. Y. Klepikov, J. Nuclear Mater. 283-287, 1 (2000).

[9] A. Niechajowicz and A. Tobota, J. Mater. Proc. Technol. 106, 1 (2000).

[10] L. Storojeva, D. Ponge, R. Kaspar, and D. Raabe, Acta Mater. 52, 2209 (2004).

[11] H. Beladi and P. Hodgson, Scripta Mater. 56, 12 (2007).

[12] R. Narayanasamy, V. Anandakrishnan, and K. S. Pandey, Mater. Sci. Eng. A 494, 337 (2008). 
[13] H. W. Mead and C.E. Birchenal, Trans. TMS-AIME 206, 1336 (1956).

[14] P. J. Wray, Met. Trans. A 13, 125 (1982).

[15] W. Shizhong, Z. Jinhua, and R. Long, Mater. Design, 27, 1 (2006).

[16] Key to steel, The world's Most Compherensive Steel Database, 2009.

[17] Y.F. Shen, W. Y. Xue, Y.D. Wang, Y.D. Liu, and L. Zuo, Mater. Sci. Eng. A 496, 383 (2008).

[18] J.H. Chen, G.Z. Wang, and S. H. Hu, Metall. Mater. Trans. A 32, 5 (2001).

[19] O. Yoo, Y. J. Ohb, B. S. Lee, and S. W. Nama, Mater. Sci. Eng. A 405, 147 (2005).

[20] Y. Murata, M. Morinaga, R. Hashizuma, K. Takami, T. Azuma, Y. Tanaka, and T. Ishiguro, Mater. Sci. Eng. A 282, 251 (2000)

[21] S. Sjöström, Mater. Sci. Technol. 1, 10 (1985).

[22] B. Hildenwall, Phd. Thesis, Linkoping University 1979.

[23] D. C. Collinson, P. D. Hodgson, and C. H. J. Davies, in: Thermec'97, Wollongong, Australia, 1997, p. 483.

[24] Y. Murata, M. Morinaga, R. Hashizume, K. Takami, T. Azuma, Y. Tanaka, and T. Ishiguro, Mater. Sci. Eng. A 282, 251 (2000).

[25] F. D. Torre, R. Laopvok, J. Sandlin, P. Thomson, C. Davies, and E. Pereloma, Acta Mater. 52, 16 (2004).

[26] G. Cao, X. Chen, J. W. Kysar, D. Lee, and Y.X. Gan, Mech. Res. Commun., 34, 275 (2007).
[27] G. Zamfirova, V. Lorenzo, R. Benavente, and J. M. Perena, J. Appl. Polym. Sci. 88, 1794 (2003).

[28] J. Datsko, L. Hartwig, and B. Mc Clory, J. Mater. Eng. Perform. 10, 6 (2001).

[29] E. J. Pavlina and C. J. Van Tyne, J. Mater. Eng. Perform. 17, 6 (2008).

[30] W. D. Callister, Materials Science and Engineering, 5th Edn. John Wiley and Sons, New York 2000, p. 139.

[31] B. H.-J. Sim, Y. B. Lee, and W. J. Nam, J. Mater. Sci. 39, 1849 (2004).

[32] C.D. Preininger, J. Nuclear Mater. 307-311, 514 (2002).

[33] A. Sato and M. Meshii, Acta Mater. 21, 753 (1973).

[34] A. Uenishi and C. Teodosiu, Acta Mater. 51, 4437 (2003).

[35] P. Lukac and J. Balik, Key Eng. Mater. 97/98, 307 (1994).

[36] K. Mathis and Z. Trojanova, Kovove Mater. 43, 238 (2005).

[37] H. Suzuki, in: F. Nabarro (ed.), Dislocations in Solids, Vol. 4, North-Holland Publ. C, Amsterdam 1979, p. 193.

[38] H. Neuhauser and C. Schwink, in R. W. Cahn, P. Haasen, E. J. Kramer, H. Mughrabi (eds.), Materials Science and Technology, Vol. 4, Plastic Deformation and Fracture of Materials, VCH, Weinheim 1993, p. 191.

[39] L.E. Lindgren, K. Domkin, and S. Hansson, Mech. Mater. 40, 11 (2008). 